\title{
THE SKIN END-ORGANS OF THE TRIGEMINUS AND LATERALIS NERVES OF BDELLOSTOMA DOMBEYI.
}

BY

\section{HOWARD AYERS AND JULIA WORTHINGTON.}

\section{WITH 10 FrGURES.}

Owing to the noteworthy and rather complicated internal relationship of the Trigemius and Acustico-Lateralis nerves of Bdellostoma, it has seemed best to publish a brief abstract of the results which a study of the peripheral terminations of these nerves has produced. The material on which the study is based consists of preparations made by the Golgi, the methylene blue, and the gold chloride methods, as well as sections stained with various coal-tar colors.

Stated briefly, the distribution of these nerves in the head of Bdellostoma is as follows: the skin territories of the dorsal part of the head cephalad of the brain, of the four tentacles, of the rim of the nasal tube, and of the upper part of the lip, are innervated by the trigeminus. The dorsal skin over the fore part of the brain and a little laterad of it is innervated by the lateralis posterior. The skin at the side of the head in front of the brain is within the territory belonging to both sets of nerves. Both trigeminus and lateralis fibers run to it through a common trunk, the lateralis component of which is the lateralis anterior.

The sense organs of the trigeminus described in this paper are those occurring in the tentacles and the rim of the nasal tube, while the sense organs of the lateralis are those found in the lateral line canals. Both kinds have been compared with those found in the territory supplied by both nerves. In this way we have sought to obtain a clear discrimination of the two kinds of organs.

The skin of Bdellostoma consists of two primary layers, a dermis and an epidermis. Essential agreement in structure with the skin of Petromyzon is the noteworthy fact.

The epidermis, when studied in sections stained with the usual general stains, such as hæmatoxylin or carmine, is seen to be composed of an Anerican Jotruxal of Axatomy.- Vol. ViI. 
inner and an outer layer. The outer layer is, for the most part, composed of larger cells so arranged as to produce a smooth surface. As its cells die and fall away from the surface they are replaced from the inner layer. Numerous migrant mucous cells push their way from the basement membrane, lying. on the dermis, outward, until they reach the surface where they break and discharge their contents upon the surface of the skin. With the exception of the mucous cells, the elements of the epidermis are relatively stationary.

Besides the more numerous polyhedral cells which make up the bulk of the epidermis, and omitting the mucous cells already mentioned, the other cell types met with are the scnsory cells and supporting cells of the sense organs, the long club-shaped cells or palisade cells, and the undifferentiated cells from which all of these are produced. When, instear of using a hæmatoxylin or a carmine stain, some of the coal-tar colors are used, it is seen that the inner layer of the epidermis is itself sharply divided into two layers, a broad inner layer resting directly upon the basement membrane, and an outer layer of varying width. In material that has been hardened in chromic acid, this outer layer, the middle layer. of the epidermis, does not stain with aniline green, Lyons blue, toluidin blue, or saffranin, but takes picric acid easily and holds it well. As the superficial layer, composed of larger cells, stains in the same color as the inner layer, it is thus shown that the division between outer and middle layers is not clean cut, as it looks in hæmatoxylin sections, for patches of yellow can be seen intruding into the outer layer, and lying between its cells. In Golgi sections a similar division is seen. The impregnation is extremely capricious in its action, here as elsewhere; sometimes the entire inner layer will be blackened, sometimes the entire middle layer. When this latter is the case, the blackening will sometimes extend far up into the outer layer, showing better than the color stains how deep the dovetailing of outer and middle layers really is.

\section{The Trighandes Exdings.}

Free endings.-First and simplest of all are what appear to be free endings. The fine fibers of the nerve, on entering the epidermis, divide into still finer fibrils, some of even diameter, some beaded. Some of these fibrils take a comparatively straight course through the epidermis, and end in the outer layer, without forming nerre plates in connection with 
any cell, and apparently without connecting with the epithelial cells in any way (Figs. 1 and 2 ) ; others, after running out a little way through the epidermis, turn and run parallel to the basement membrane, giving out in their course numerous fine fibrils that run, some mesad, some ectad. Some of these fine fibrils end in contact with cells, others, apparently, end free between the cells. Fig. 1, drawn from the common territory, also illustrates these relations as they exist in the tentacles.

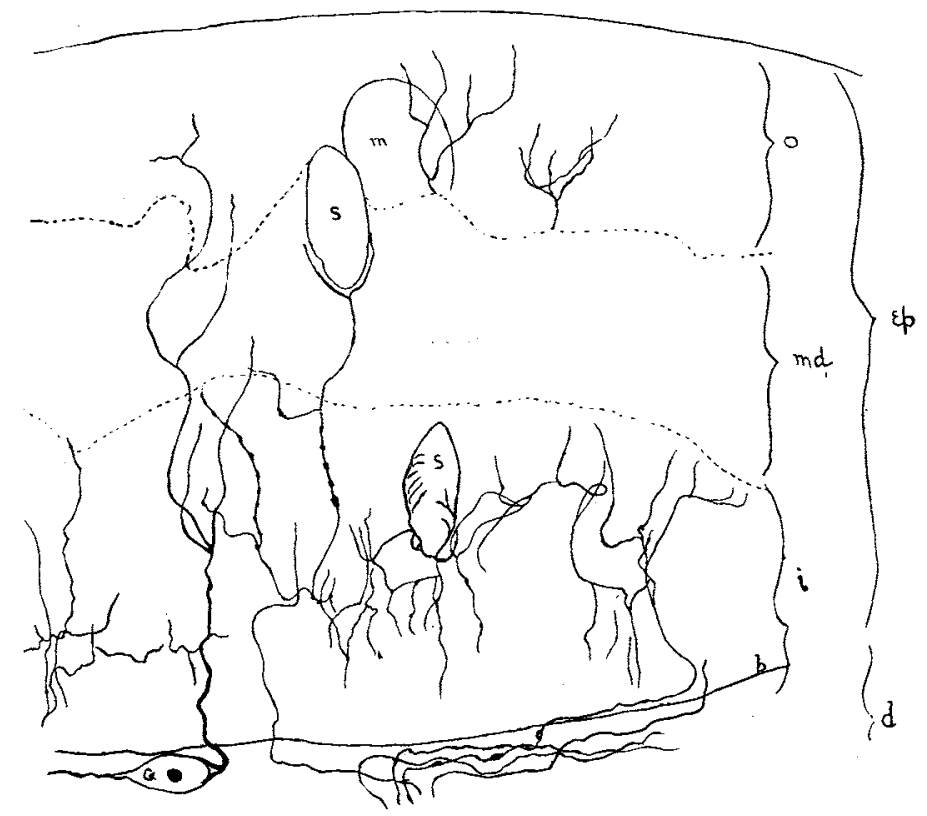

Fig. 1. Cross-section of skin of adult Bdellostoma through territory innervated by both trigeminus and lateralis fibers. Golgi preparation. $b=$ basement membrane, $d=$ dermis, $e p=$ epidermis, $G=$ ganglion cell, $i=$ inner layer of epidermis, $m=$ mucous cell, $m d=$ middle layer of epidermis, $o=$ outer layer of epidermis, $s=$ sensory cell. $\times 153$.

Nerve end cells. - The single cells in connection with which trigeminus fibers end, may be divided roughly into two classes, large cells and small cells. The small cells (Fig. 3) oecur in either the inner or middle layers, and are very numerous. Many of them are oval, though some are conical as in Fig. 3, and taper to a sharp point at the apex. The nerve comes in contact with these cells at their proximal end; sometimes it forks (Fig. 3), sending a branch to lie against the cell on either side, sometimes it forms a small plate at the base of the cell, and sometimes it appears to penetrate 
the cell, where it divides into numerous fine fibrils some of which lie parallel to each other (Figs. 1 and 3). The large cells (Fig. 4) are long
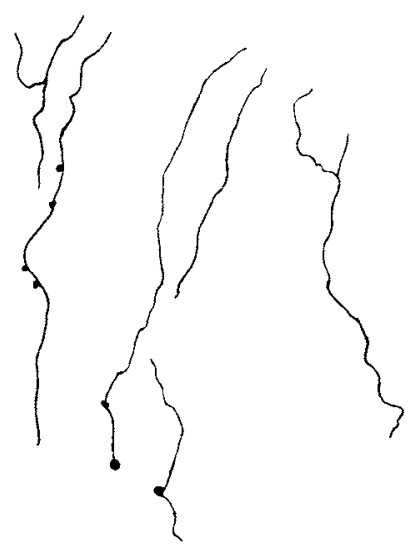

FIG. 2.

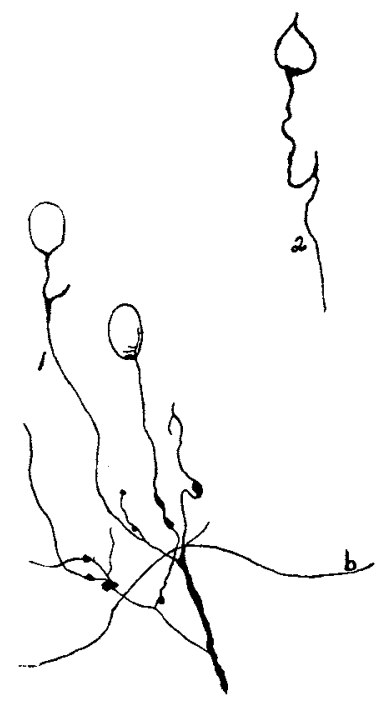

FIG. 3.
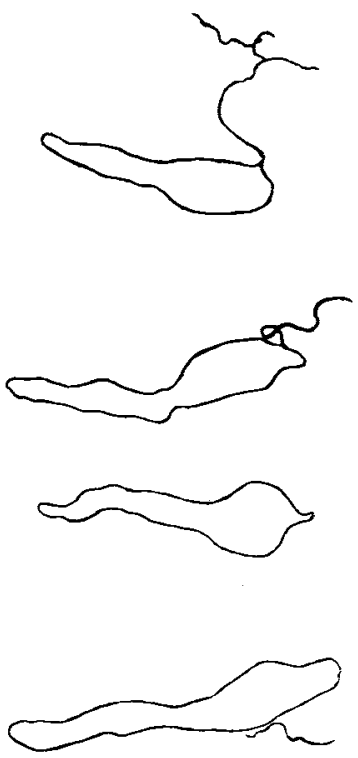

FIG. 4.

FIG. 2. Free nerve endings in the tenacle. $\times 533$.

Fig. 3. Small sensory cells in tentacle. $b=$ basement membrane. 1 and 2 did not lie in the same field. $\times 533$.

Fig. 4. Large sensory cells in the tenacle. $\times 733$.

and narrow, club-shaped, generally wider at the proximal than at the distal end. They lie, either in the inner layer, or partly in the inner 
layer, and partly in the middle one. The nerve enters them on the side, not far from the proximal end. There are comparatively few of these cells in the tentacles, and these few are comparatively small; in the skin of the head they are much larger and more numerous.

\section{The Lateralis Endings.}

Although numerous investigators have searched for lateral line organs in Bdellostoma, both the organs and their canals have hitherto remained

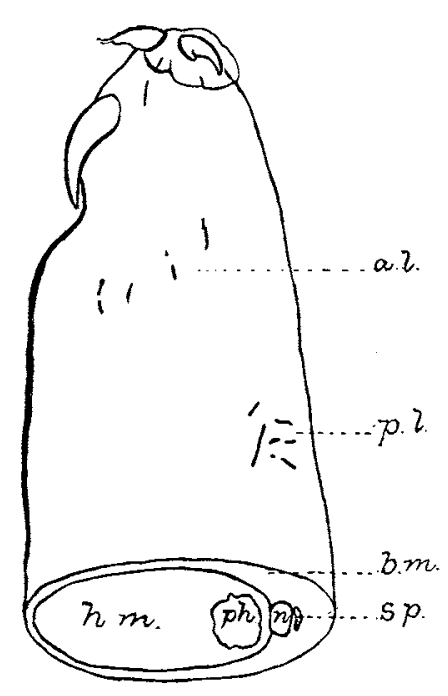

Fig. 5.

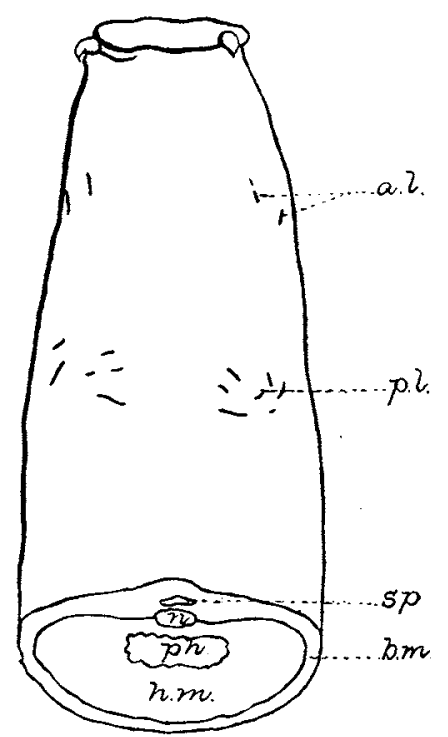

Fig. 6 .

Fig. 5. Side view of head of young Bdellostoma, 11 inches long, preserved in chronic acid. a. $l=$ anterior lateral line canals, $b . m=$ body musculature, $h$. $m$. = head musculature, $n$. = notochord, $p . h .=$ pharynx, $p . l .=$ posterior lateral line canals, $s p .=$ spinal cord. $\times 2 \%$.

Fig. 6. Dorsal view of same head. a. $l==$ anterior lateral line canals, b. $m$. = body musculature, $h$. $m$. = head musculature, $n=$ notochord, $p h=$ pharynx, $p . l .=$ posterior lateral line canals, $s p .=$ spinal cord. $\times 2 \%$.

undiscovered. The presence of lateral line canals in Bdellostoma is exceedingly interesting and noteworthy. The sense organs belonging to the Acustico-lateral system have been long recognized as present in the Petromyzonts, but in the Bdellostomids these structures have eluded all observers. Their existence in the latter forms is interesting and important because it demonstrates the presence of the surface organs from which 
the ear sense organs arose, and shows them to be fully formed and functional in the lowest rertebrates above Amphioxus. The Acustico-lateral system of nerves and sense organs in Bdellostoma is as a whole not better dereloped, in comparison with the fishes (e.g., Elasmobranchs), than is the Marsipobranch ear in comparison with the Elasmobranch ear. As we shall show, it stands as an intermediate stage between an earlier and still undescribed condition, and that found in higher forms. The facts relative to the Acustico-lateral system of Bdellostoma constitute another

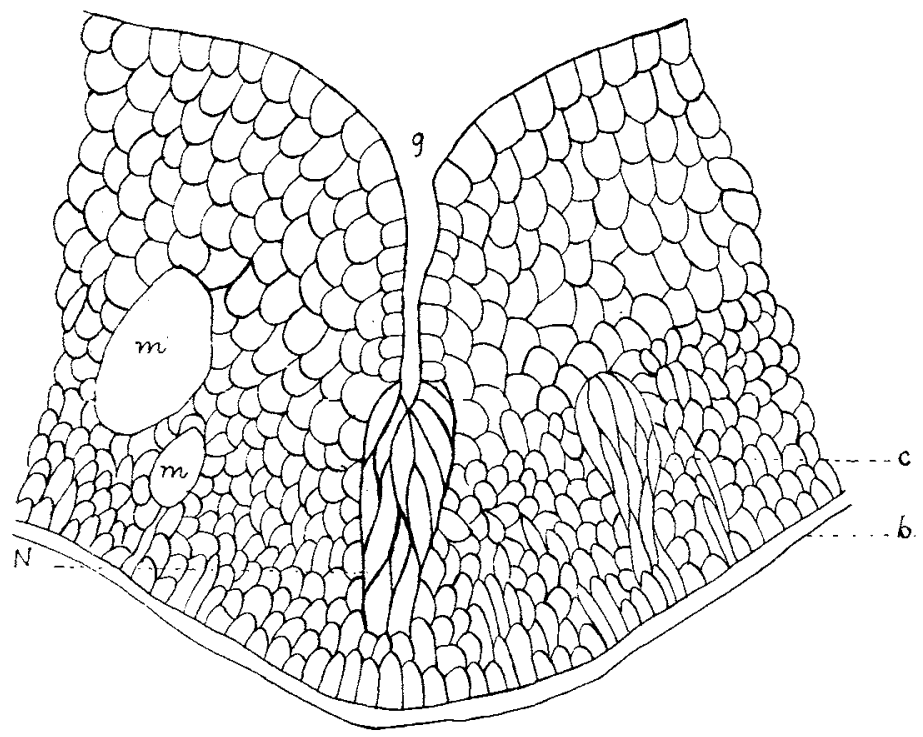

FIG. 7. Cross-section of epidermis of young Bdellostoma, 11 inches long, through lateral line canal. Preserved in formalin. $b=$ basement membrane, $c=$ spindle-cell neuromast at side of dermal groove, $g=$ lateral line canal, $m=$ mucous cell, $X=$ central spindle-cell neuromast ridge. $\times 333$.

and an important contribution to the growing evidence that the Marsipobranchs are not degenerate forms, but occupy a place in the direct line of descent of the phrium from the ancestral form.

In Bdellostoma the canals of the lateral line system are certainly diffcult to find largely because they are exceedingly small, and the surface indications are so faint that even in heads preserved in chromic acid, only an eve that knows exactly where to look and what to expect can detect them in the full-grown adult. In the young hagfish not more than eleven or twelve inches long. the chromic acid treatment shows them much more plainly. 
The canals are arranged in two groups, an anterior and a posterior one, in the dorso-lateral territory of the head, corresponding to the anterior and posterior lateralis nerves by which they are innervated. Figs. 5 and 6 show the position of these groups on the head. The anterior group of canals is composed of four, occasionally three or five short canals, nearly equidistant from each other. This group of canals is located on the side of the head in front of the eye, of its side of the boty. The cephalic end of the most ventral canal is slightly caudad of the hind end of the most dorsal one (Fig. 5). The posterior group lies on the dorsal surface of the head and consists of two divisions; the three (occasionally two) inner canals run meso-laterad, and the outer ones run at a slight angle to the long axis of the body (Fig. 6).

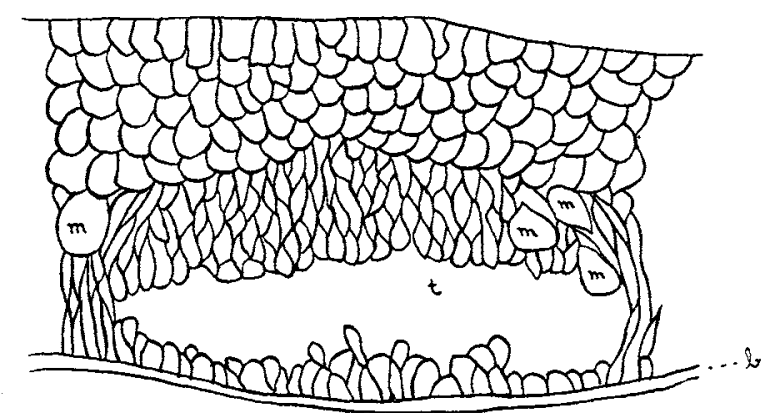

Fig. 8. Cross-section of epidermis of young Bdellostoma, 11 inches long, close to lateral line canal. Preserved in chromic acid. $b=$ basement membrane, $m=$ mucous cell, $t$ tube above dermal groove. $\times 333$.

Cross-sections through the canals show an interesting and rather peculiar state of affairs, and also a condition that differs according to the original preservative used. Fig. 7 is a cross-section through one of the dorsal canals of a young hagfish about eleven inches long. The head from which it was taken was preserved in formalin. The canal itself (Fig. $7, g$ ) is seen as a deep, narrow groove in the outer layer of the epidermis. In the figure its bottom is formed by the outer ends of a group of long, slender spindle cells (Fig. $7, c$ ), grouped to form a fusiform body. In studying serial sections, however, this group of spindleshaped cells is found to extend along the entire bottom of the canal. In some sections it extends down to the basement membrane, in others only about one-half the distance. There is a distinct line of cleavage down the center of this ridge of spindle cells, so that in some sections it sep- 
arates in halves, the carity of the canal being continuous with the break in the ridge. Beneath the canal and ridge is a very decided depression of the basement membrane, so that the entire apparatus, canal and ridge together, rests in a groore of the dermis (Fig. 10). This groove does not terminate with the canal above it, but extends a short distance, sometimes thirty microns, sometimes one hundred and thirty, beyond it at each end. Moreover, where the surface canal is interrupted (Figs. 5 and 6 ), sections show the groove beneath to be continuous.

At one side of the dermal groove in Fig. 7 is seen a second body of spindle-shaped cells, inclined towards the canal. These side bundles are formed of a row of club-shaped bodies; sometimes they are continuous

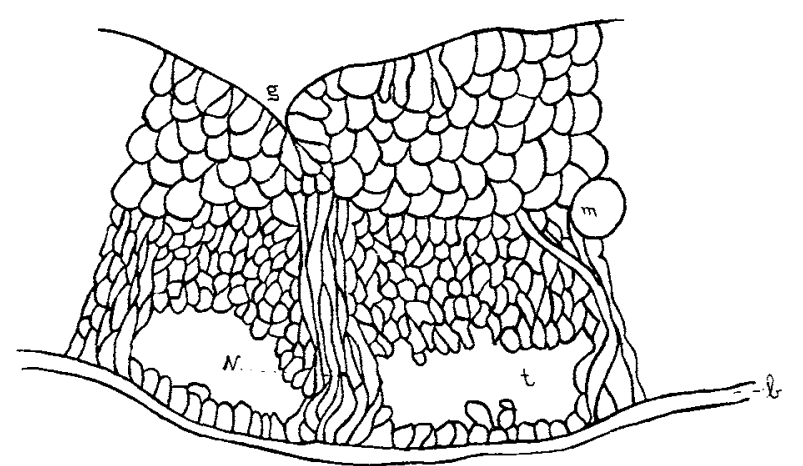

FiG. 9. Cross-section of epidermis of young Bdellostoma, 11 inches long, through lateral line canal. Preserved in chromic acid. $b=$ basement membrane, $g=$ lateral line canal, $m=$ mucous cell, $N=$ spindle-cell ridge, $t=$ tube beneath canal and above dermal groove. $\times 333$.

ridges, shorter, howerer, than the central ridge. Like it they have a definite line of cleavage down the center, and are sometimes connected by a branch opening directly with the canal.

Similar club-shaped bundles of spindle cells are also found outside of the dermal groove. They are numerous in the territory of the lateralis anterior, but much less so in that of the lateralis posterior. Nerre fibers run into the bundles, and they are undoubtedly genuine neuromasts.

In addition to these neuromasts, single sensory cells are found in the territory of the dermal groove, (Fig. 10,s). They are larger than the epithelial cells about them, are bluntly conical in shape, and do not stain readily. These sense cells are not abundant, but a more successful method of staining may show them to be more numerous than they 
appear at present. They have been found outside of the dermal groove as well as within it.

When instead of skin preserved in formalin, skin of a young hagfish that has been preserved in chromic acid is used, startlingly different results are obtained. The essential features, the deep surface canal of the epidermis, the spindle-celled ridge, the dermal groove, are all present; but in addition to these the chromic acid causes the inner epidermal layer tc separate into two parts along what appears to be a definite line of weakness, and thus forms closed tubes that appear between the dermal groove

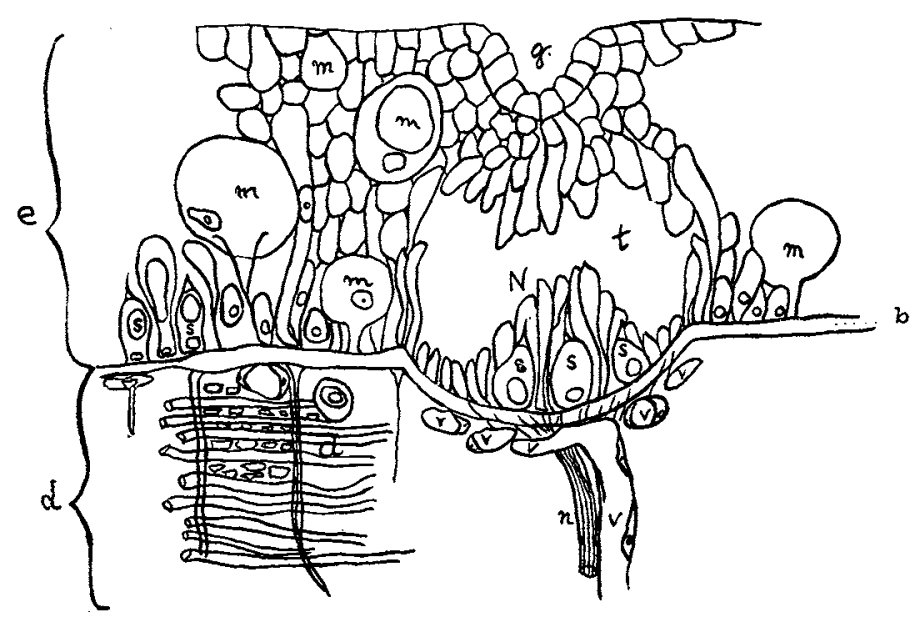

FIG. 10. Cross-section of skin through lateral line canal of young Bdellostoma, 11 inches long, preserved in chromic acid. $b=$ basement membrane, $d=$ dermis, $e=$ epidermis, $g=$ lateral line canal, $m=$ mucous cell, $n=$ nerve bundle, $N=$ spindle-cell ridge (broken across), $s=$ single sensory cell, $t=$ tube beneath canal, $v=$ blood-vessel. $=153$.

and the superficial canal (Figs. 8, 9, and 10,t). The closed tubes are as long as the dermal grooves, and consequently longer than the surface canals. Fig. 8 is a typical section of one of these tubes just before its end, after passing the end of the canal, and this same appearance is also found in the territory of the closed tube in the inter-spaces shown in Figs. 5 and 6 in which the surface canal is interrupted. The closed tube is, for the most part, separated by only a single layer of small cells from the bascment membrane. Above the lumen of the tube are several layers of small cells before the large celled layer of the epidermis is reached. The sides of the tube are usually bounded by long slender cells, and its roof, in this section, contains several mucous cells. 
In chromic acid material the canal has sometimes the appearance of a pinching in of the epithelium, as in Fig. 9, and at others the appearance of a well-formed groove as in Fig. 10 ; in formalin sections it is ordinarily deeper and narrower, as in Fig. \%. The central ridge of spindle cells has the same relation to the canal in chromic acid sections as is shown in those preserved in formalin, but in Fig. 9, where the sides of the canal have been pinched together, this relation is not so easily recognizable.

In some sections the ridge runs only as far as the lumen (Fig. 10), and in others, as in Fig. 9, it crosses the lumen to dovetail into long slender cells of the same kind resting on the basement membrane, thus bisecting the tube. This bundle of spindle cells has, in cross-section, the appearance of a plug, and the line of cleavage down the center is occasionally well marked.

There is still a third typical cross-section of the tube (Fig. 10). In it the spindle-celled ridge has apparently been torn in two across the middle along a plane parallel with the surface, leaving a decided ridge rising from the floor of the tube. In this lower ridge are found several single sensory cells (Fig. 10,s).

From the preceding statements two facts stand out prominently. The first is the embryonic condition of the canals as compared with the typical canals of higher vertebrates. In Bdellostoma the canals remain throughout life entirely within the epidermis. At no stage of growth do they acquire a dermal sheath. They thus represent in their adult condition a stage of growth present only in the embryos of higher vertelorates. The second is the relatively low stage of differentiation of the sense organs. The dermis is depressed underneath the canals, but the edges of the grooves thus formed do not grow upward to enclose the epithelial canal. The dermal groove is never deep enough to enclose the sense organ.

Cinchanati, O., April, 1907. 